\title{
Investigation of Mechanical Properties of Sansevieria cylindrica Fiber/Polyester Composites
}

\author{
Balasubramani Subramaniam (D), ${ }^{1}$ Manickavasagam V. M (D), \\ Paul Theophilus Rajakumar I, ${ }^{3}$ P.Anantha Christu Raj, ${ }^{4}$ Bharath V G, ${ }^{5}$ J. Madhusudhanan, ${ }^{6}$ \\ Amit Kumar Sharma $\mathbb{D}^{7}{ }^{7}$ Pravin Patil, ${ }^{8}$ and Gizachew Balcha Assefa ${ }^{9}$ \\ ${ }^{1}$ Department of Mechatronics Engineering, Sri Krishna College of Engineering and Technology, Coimbatore-641008, India \\ ${ }^{2}$ Department of Mechanical Engineering, Sri Sairam Engineering College, Chennai 600044, Tamilnadu, India \\ ${ }^{3}$ Department of Mechanical Engineering, Panimalar Institute of Technology, Chennai 600123, Tamilnadu, India \\ ${ }^{4}$ Department of Robotics Engineering, Karunya Institute of Technology and Sciences, Coimbatore 641114, Tamil Nadu, India \\ ${ }^{5}$ Department of Mechanical Engineering, Brindavan College of Engineering, Bengaluru 560063, Karnataka, India \\ ${ }^{6}$ Department of Biotechnology, Anand Institute of Higher Technology, Chennai 603301, TamilNadu, India \\ ${ }^{7}$ Department of Physics, D. A. V. (PG) College, Dehradun 248001, Uttarakhand, India \\ ${ }^{8}$ Department of Mechanical Engineering, Graphic Era Deemed to be University, Dehradun 248002, Uttrakhand, India \\ ${ }^{9}$ Department of Chemical Engineering, College of Biological and Chemical Engineering, \\ Addis Ababa Science and Technology University, Addis Ababa, Ethiopia
}

Correspondence should be addressed to Balasubramani Subramaniam; balumecadcam@gmail.com

Received 9 January 2022; Revised 1 February 2022; Accepted 2 February 2022; Published 28 February 2022

Academic Editor: V. Vijayan

Copyright (c) 2022 Balasubramani Subramaniam et al. This is an open access article distributed under the Creative Commons Attribution License, which permits unrestricted use, distribution, and reproduction in any medium, provided the original work is properly cited.

\begin{abstract}
Natural fiber-reinforced composites are the most cost-effective and environmentally friendly alternative to industrial applications. Composite materials reinforced with Sansevieria cylindrica (SC) fibers were developed in this research work. These fibers were chosen for their outstanding mechanical qualities. Compression moulding was used to create composite materials. Each leaf on a Sansevieria cylindrica plant is 20 to $30 \mathrm{~mm}$ thick, with a height of 1000 to $2000 \mathrm{~mm}$. The Sansevieria cylindrica (SC) fibers were used as chemically treated fibers and untreated fibers to produce the composites. The tensile strength, hardness, and impact strength of various fiber weight $\%$ of composites $(20 \%, 30 \%, 40 \%$, and $50 \%)$ were calculated. From the tested results, the maximum tensile strength achieved in $40 \mathrm{wt} \%$ of treated SC fiber composites is $85.7 \mathrm{MPa}$. The maximum hardness is found in $40 \mathrm{wt} \%$ of composites in both treated and untreated fiber composites. The $40 \mathrm{wt} \%$ of composites gives a better impact energy of $9.4 \mathrm{~J} / \mathrm{cm}^{2}$.The SC fiber polyester composites have superior interfacial bonding and give maximal strength in treated SC fiber composites. The fiber treatment delivers greater strength than the untreated fiber, according to this study. The treated SC fibers have better strength and good bonding between the fiber and matrix to produce the composite materials.
\end{abstract}

\section{Introduction}

Composite materials play an essential part in the industries as a replacement for traditional materials. The current research focuses on the creation of newer, better, and more cost-effective composites. The usage of synthetic materials in composites may have an impact on the environment and cause other problems. To solve these issues, natural components such as fibers are employed in polymer composites. Natural fiber's widespread availability has prompted researchers to produce natural fiber-reinforced composites. The efficient use of resources such as natural materials and their products is essential for global development. The reinforcing materials in composites provide the main loadcarrying part, providing excellent quality and solidity as well as protection from twisting and breaking under the linked 
load. Composite material exhibits a blend of the greatest features of each particular material. The continuous phase is formed by the matrix material, whereas the dispersed phase is formed by the reinforcements [1-5].

All of the major sectors, including automobiles, aircraft, home appliances, and aeronautical, are currently using composite materials. The composite material was chosen because it has higher mechanical qualities, corrosion resistance, and a pleasing look, is easy to manufacture, and has a longer life span. The unsaturated polyester resin is a lowcost thermoset material that is commonly utilised due to its good processability and cross-linking tendency, as well as its good mechanical qualities. Polyester resin is an aesthetically pleasing material that may be used to make composite products at a low cost. This matrix material is mostly preferred over advanced technical applications due to the superiority of polymer mixed material, which is easy to make and at a reasonable cost [6-10].

Hornsby et al. investigated the microstructure and mechanical properties of flax and wheat straw fiber-filled polypropylene composites. The flax fiber has stronger interfacial adhesion with the resin, resulting in higher tensile yield strength and Charpy toughness. Furthermore, the results demonstrated that strengthening the interfacial adhesion between the fiber and resin by chemically treating the fiber with $5 \mathrm{wt}$ percent maleic anhydride boosted the strength [3].

Luo and Netravali investigated the mechanical properties, such as tensile and flexural properties, of pineapple fiber-reinforced composites. The authors concluded that composites' tensile and flexural strengths are significantly better in the longitudinal direction than in the transverse direction based on the findings. Fiber pull out has been identified as a result of poor fiber-matrix interfacial bonding caused by fiber fibrillation. The authors also discovered that nonisothermal crystallisation kinetics, crystallinity, and thermal degradation of the resin have no effect on pineapple fibers $[4,11]$.

Sreenivasan et al. studied the mechanical characteristics of composite plates which were determined with various fiber aspect ratios and weight fractions. Mechanical qualities such as tensile, flexural, and impact properties increased as fiber length grew, but further increasing the fiber length resulted in a restriction in properties. The findings demonstrated that the strength values of composites increase in a predictable pattern, with the property increasing as the weight percentage of the fiber increases and subsequently decreasing as the fiber weight $\%$ increases [12].

Sathishkumar et al. investigated the composite materials made with snake grass fibers which are one such capable material that may be used to replace traditional and synthetic materials in practical applications. The volume fraction enhances the tensile and flexural strengths and modulus of the snake grass fiber-reinforced composite, according to the testing results [5].

Rajesh et al. carried out chemical treatments with a $10 \%$ $\mathrm{NaOH}$ solution and $\mathrm{H}_{2} \mathrm{O}_{2}$. The tensile strength of treated fiber-reinforced polymer composites was higher than that of untreated fiber-reinforced composites. The treated fiber has a $17 \%$ higher flexural strength than plain polylactic acid matrix composites. Untreated sisal/polylactic acid matrix composites showed much higher thermal deterioration than treated fiber-reinforced composites [6]. Venkatesha Gupta et al. investigated the mechanical characteristics of sisal/ hemp fiber-reinforced epoxy composites. The fibers were treated as $10 \%$ sodium hydroxide $(\mathrm{NaOH})$. Compression moulding was used to create fiber-reinforced composites in accordance with ASTM specifications. The mechanical properties are improved due to the chemical treatment of the fiber [13].

Many studies reported the mechanical properties of fiber-reinforced polymer composites. They improve the mechanical properties with the addition of reinforcements with the proper length of the fiber and volume of the fiber $[14,15]$. The manufacturing of low-cost polymer composites is fabricated with the Sansevieria cylindrica (SC) fibers as the reinforcement and polyester resin as matrix material to produce the composites. The chemical treatment of fiber composites produces better properties than untreated ones. Very few literature studies report the mechanical properties of Sansevieria cylindrica fibers reinforced with polyester composites. This research work studied the mechanical properties of SC fiber-reinforced composites and also compared them with the usage of fibers that were chemically treated and untreated. The chemically treated fibers with the optimum level of fiber volume and length provide better strength compared with the other percentages of volume.

\section{Materials and Methods}

2.1. Materials Used. Chopped $30 \mathrm{~mm}$ Sansevieria cylindrica fibers were used as a reinforcement to produce the composites. The $30 \mathrm{~mm}$ length of Sansevieria cylindrica fibers provides better strength compared with the other lengths of the fiber. The optimum length of the fiber is selected to produce the composites [8]. The matrix material used is unsaturated polyester resin to fabricate the composite. Methyl ethyl ketone is used as curing catalyst, and naphthenate is used as accelerator.

2.2. Fiber Production Process. The SC plant was beaten with a hammer and dried in the sun for one day to remove the moisture content. The method begins with hammering to remove the fleshy layer, after which the individual fibers are retrieved by hand and shown in Figure 1. The SC fiber is $2.07 * 105 \mathrm{~m}$ thick, and density is $0.9 \mathrm{~g} / \mathrm{cm}^{3}[8]$.

2.3. Fiber Surface Treatment. The $\mathrm{NaOH}$ treatment caused hemicellulose in the cellulosic fiber to swell even more, and other contaminants were eliminated from the fiber surface. Because of the $\mathrm{NaOH}$ treatment, the cellulose microfibrils remain unaltered. Surface contaminants are removed in order to improve mechanical qualities, fiber wetting characteristics, and fiber-matrix surface bonding in composite applications [8].The chemical properties of SC fiber values are tabulated in Table 1. 


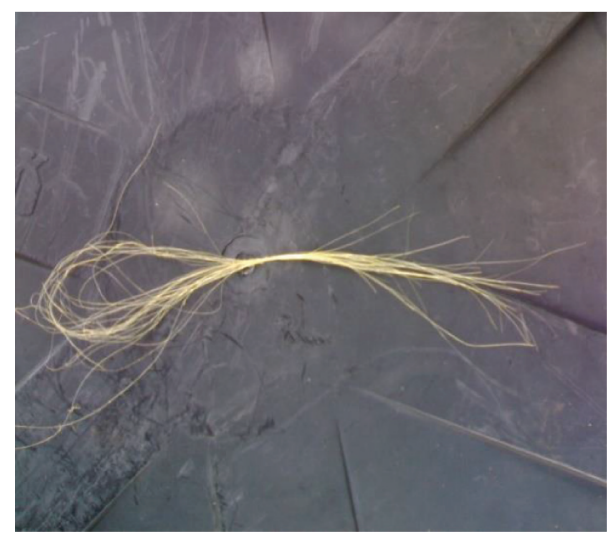

Figure 1: Sansevieria cylindrica (SC) fiber.

Table 1: Chemical properties of the Sansevieria cylindrica fiber.

\begin{tabular}{lccccc}
\hline Fiber category & Cellulose (\%) & Hemicellulose (\%) & Lignin (\%) & Wax (\%) & Moisture (\%) \\
\hline Raw fiber & 79.7 & 10.13 & 3.18 & 0.09 & 6.06 \\
$10 \%$ NaoH treated & 82.6 & 6.95 & 3.98 & 0.07 & 8.03 \\
\hline
\end{tabular}

2.4. Preparation of Composites. Composites were made using the compression moulding technique. The chemically treated SC fibers were used for the preparation of composites.

The composites were randomly distributed with varying weight percentages $(10 \%, 20 \%, 30 \%, 40 \%$, and $50 \%)$ of the SC fiber. A great effort was taken to ensure that the fibers were distributed evenly. Hydraulic compression was used to apply a force to prepare the composites. The mould box size was $300 * 300 * 3 \mathrm{~mm}$, and the material of the mould was EN8 steel. The polyester resin was mixed with $0.5 \%$ cobalt naphthenate and $2 \%$ methyl ethyl ketone peroxide. Before pouring, the matrix solution was degassed. The matrix solution was applied using a brush, and air bubbles were removed in the sheet. Hydraulic pressure was applied to the mould at the period of 24 hours. The composites were made in the shape of a flat plate measuring $300 * 300 * 3 \mathrm{~mm}$, and they are shown in Figure 2 .

\section{Results and Discussion}

3.1. Mechanical Properties. The composites were cut for the tensile test in accordance with ASTM guidelines. The tensile test was conducted using the ASTM D638 method, and testing is carried out by applying tensile load on both ends. Each test carries with three samples, and average values are noted. The ASTM D256 procedure specifies the use of Izod impact testing equipment to accomplish the impact test. Each test carries with three samples, and average values are noted. The hardness was determined using Rockwell hardness testing equipment in accordance with ASTM D785 standards. The test was conducted in five places of each sample, and average values were noted $[16,17]$.

3.2. Tensile Test. The influence of fiber treatments on the tensile characteristics of short SC fiber composites is shown in Figure 3. The tensile strength of $35.5 \mathrm{MPa}$ was obtained from the pure polyester resin plate.

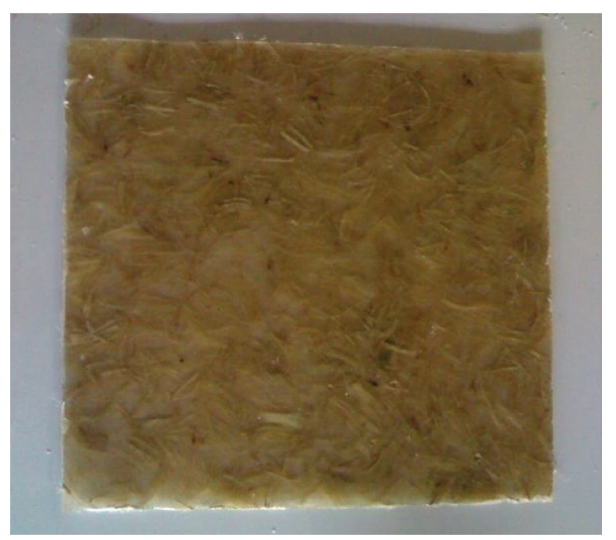

FIGURE 2: SC fiber-reinforced polyester composites.

The tensile strength of treated and untreated SC fiber composites is tabulated in Table 2. The tensile strength of the SC fiber composite has been raised to $85.7 \mathrm{MPa}$ due to the addition of treated SC fiber to the polyester matrix. The tensile strength of treated and untreated SC fiber-reinforced polyester composites against the varying wt $\%$ is plotted and shown in Figure 3. The tensile strength of treated SC fiber composites has given the higher strength. The $40 \mathrm{wt} \%$ of composites had the highest tensile strength among the treated SC fiber composites, indicating a robust interfacial bond between the SC fiber and polyester matrix. The wax, hemicelluloses, and pectin concentrations in the surface of plant fibers hindered the wetting of the fiber with the matrix [18]. The tensile load was applied to the composites, the major failure of the specimen was fiber pull out, and due to this, the voids were created. The fracture occurs in the fiber and matrix in the composites [19].

3.3. Hardness. When a load is applied to a sample, its hardness refers to the resistance has its shape permanently changed. When a composite material is subjected to a 
TABLE 2: Tensile strength of treated and untreated SC fiber composites.

\begin{tabular}{|c|c|c|c|c|}
\hline \multirow{2}{*}{ Sample name } & \multirow{2}{*}{$\mathrm{Wt} \%$ of the SC fiber } & \multicolumn{2}{|c|}{ Ultimate tensile strength $(\mathrm{MPa})$} & \multirow{2}{*}{ Elongation (\%) } \\
\hline & & Untreated SC fiber composites & Treated SC fiber composites & \\
\hline 1 & Pure polyester resin & & & 1.8 \\
\hline 2 & 10 & 38.7 & 45.8 & 7.2 \\
\hline 3 & 20 & 50.3 & 53.3 & 7.4 \\
\hline 4 & 30 & 62.8 & 67.4 & 7.5 \\
\hline 5 & 40 & 74.5 & 85.7 & 7.4 \\
\hline 6 & 50 & 66.3 & 72.6 & 7.3 \\
\hline
\end{tabular}

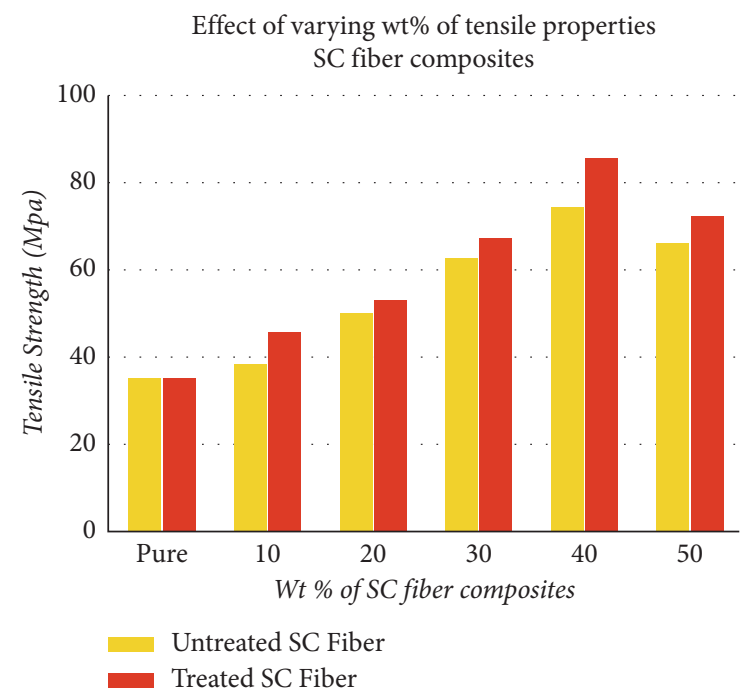

FIGURE 3: Tensile strength of treated and untreated SC fiber-reinforced polyester composites.

TABLE 3: Hardness values of treated and untreated SC fiber composites.

\begin{tabular}{lccc}
\hline \multirow{2}{*}{ Sample name } & Wt\% of the SC fiber & \multicolumn{2}{c}{ Hardness (Rockwell) } \\
& & Untreated SC fiber composites & 65 \\
1 & Pure polyester resin & 75 & 78 \\
2 & 10 & 78 & 83 \\
3 & 20 & 83 & 89 \\
4 & 30 & 86 & 92 \\
5 & 40 & 78 & 86 \\
\hline
\end{tabular}

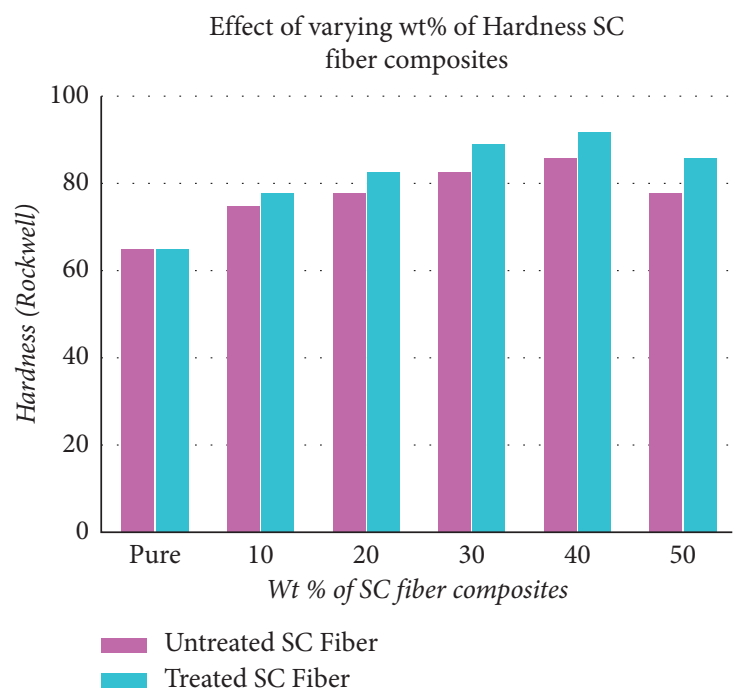

FIGURE 4: Hardness of treated and untreated SC fiber-reinforced polyester composites. 
TABLE 4: Impact strength of treated and untreated SC fiber composites.

\begin{tabular}{lccc}
\hline Sample name & Wt $\%$ of the SC fiber & \multicolumn{2}{c}{ Impact strength $\left(\mathrm{J} / \mathrm{cm}^{2}\right)$} \\
Treated SC fiber composites \\
\hline 1 & Pure polyester resin & Untreated SC fiber composites & 0.6 \\
2 & 10 & 4.7 & 4.9 \\
3 & 20 & 5.3 & 5.6 \\
4 & 30 & 6.8 & 7.4 \\
5 & 40 & 8.5 & 9.4 \\
6 & 50 & 8.3 & 8.6 \\
\hline
\end{tabular}

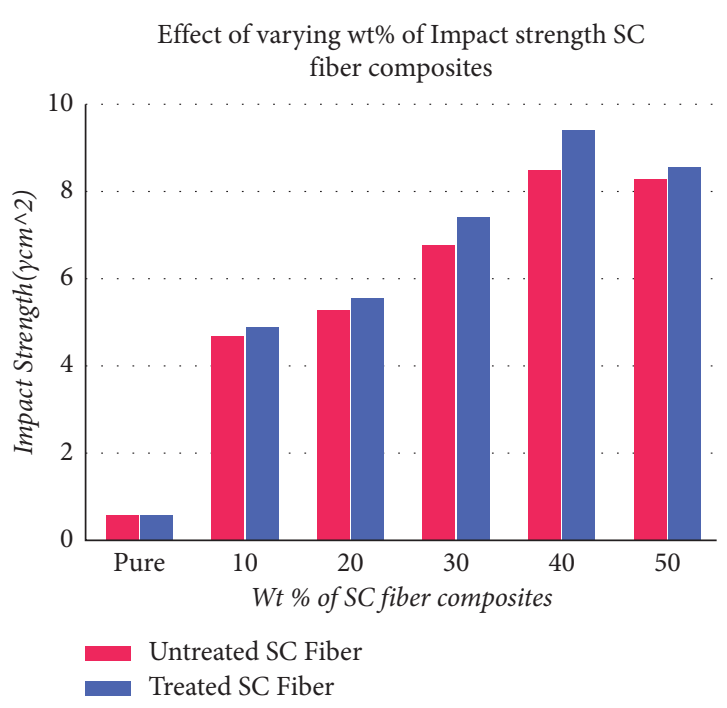

FIGURE 5: Impact strength of treated and untreated SC fiberreinforced polyester composites.

sudden impact, it indicates the composite's ability to resist crack propagation. The composite material hardness is based on the distribution of the fiber into the matrix [20]. The hardness values of treated and untreated SC fiber composites are tabulated in Table 3. The hardness of treated SC fiber composites has given the higher value. The hardness values of treated and untreated SC fiber-reinforced polyester composites against the varying $\mathrm{wt} \%$ are plotted and shown in Figure 4 . The $40 \mathrm{wt} \%$ of composites had the highest hardness among the treated SC fiber composites. It indicates that the distribution of the fiber into the matrix minimizes the voids and also better interfacial bond between the SC fiber and matrix [21].

3.4. Impact Test. The ability of the material which withstand high speed stress is called as impact resistance [22]. The impact strength values of treated and untreated SC fiber composites are tabulated in Table 4.

The impact strength is determined as the ability to absorb energy of the metal. The impact energy of $0.4 \mathrm{~J} / \mathrm{cm}^{2}$ was obtained from the pure polyester resin plate. As a result, 40 $\mathrm{wt} \%$ of composites gives better impact strength than other composites. The impact strength of treated and untreated SC fiber-reinforced polyester composites against the varying wt $\%$ is plotted and shown in Figure 5. The $40 \mathrm{wt} \%$ of composites is capable of absorbing a greater amount of energy to inhibit fracture development [19]. The material has inadequate interfacial bonding which causes microspaces between the filler and the matrix, making crack propagation simple. Under impact load, microcracks cause crack propagation [23].

\section{Conclusions}

The polymer composites with treated SC fiber and untreated SC fiber composites have been prepared with the compression moulding technique. The mechanical properties of treated SC fiber composites and untreated SC fiber composites with varying wt $\%$ of composites are evaluated. The major results are as follows. The maximum tensile strength achieved in $40 \mathrm{wt} \%$ of treated SC fiber composites is 85.7 $\mathrm{MPa}$. Further addition of the fiber reduces the strength of composites. The $40 \mathrm{wt} \%$ of composites gives the maximum hardness in both treated and untreated fiber composites. The $40 \mathrm{wt} \%$ of composites gives a better impact energy of $9.4 \mathrm{~J} / \mathrm{cm}^{2}$. Further addition of composites reduces the strength of composites due to micropores and crack initiation of composites. The mechanical properties of SC fiber polyester composites have better interfacial bonding and provide the maximum strength in the treated SC fiber composites. The tensile strength, hardness, and impact energy of treated SC fiber composites showed the maximum value when compared to untreated fiber composites. From this research, it reveals that the fiber treatment provides better strength than the untreated one. The treated SC fibers have better strength and good bonding between the fiber and matrix to produce the composite materials. The $40 \mathrm{wt} \%$ of fiber composites has better properties than other composites.

\section{Data Availability}

The data used to support the findings of this study are included within the article.

\section{Conflicts of Interest}

The authors declare that there are no conflicts of interest regarding the publication of this paper.

\section{Acknowledgments}

The publication is only for the academic purpose of Addis Ababa Science and Technology University, Ethiopia. 


\section{References}

[1] N. Saba, M. T. Paridah, and M Jawaid, "Mechanical properties of kenaf fibre reinforced polymer composite: a review," Construction and Building Materials, vol. 76, pp. 87-96, 2015.

[2] S. Taj, M. A. Munawar, and S. Khan, "Natural fiber-reinforced polymer composites," Proceedingsof the-Pakistan Academy of Sciences, vol. 44, no. 2, 129 pages, 2007.

[3] P. R. Hornsby, E. Hinrichsen, and K. Tarverdi, "Preparation and properties of polypropylene composites reinforced with wheat and flax straw fibres: part I fibre characterization," Journal of Materials Science, vol. 32, no. 2, pp. 443-449, 1997.

[4] S. Luo and A. N. Netravali, "Mechanical and thermal properties of environment-friendly? green? composites made from pineapple leaf fibers and poly(hydroxybutyrate-co-valerate) resin," Polymer Composites, vol. 20, no. 3, pp. 367-378, 1999.

[5] T. P. Sathishkumar, P. Navaneethakrishnan, and S. Shankar, "Tensile and flexural properties of snake grass natural fiber reinforced isophthallic polyester composites," Composites Science and Technology, vol. 72, no. 10, pp. 1183-1190, 2012.

[6] G. Rajesh, A. R. Prasad, and A. Gupta, "Mechanical and degradation properties of successive alkali treated completely biodegradable sisal fiber reinforced poly lactic acid composites," Journal of Reinforced Plastics and Composites, vol. 34, no. 12, pp. 951-961, 2015.

[7] L. Boopathi, P. S. Sampath, and K. Mylsamy, "Investigation of physical, chemical and mechanical properties of raw and alkali treated Borassus fruit fiber," Composites Part B: Engineering, vol. 43, no. 8, pp. 3044-3052, 2012.

[8] N. Balaji, S. Balasubramani, T. Ramakrishnan, and Y. Sureshbabu, "Experimental investigation of chemical and tensile properties of sansevieria cylindrica fiber composites," in Materials Science Forumvol. 979, , pp. 58-62, Trans Tech Publications Ltd, 2020.

[9] T. Ramakrishnan, M. S. Babu, S. Balasubramani, K. Manickaraj, and R. Jeyakumar, "Effect of fiber orientation and mechanical properties of natural fiber reinforced polymer composites-A review," Paideuma journal, vol. 14, no. 3, pp. 17-23, 2021.

[10] T. Ramakrishnan, R. S. Kumar, S. Balasubramani, R. Jeyakumar, S. J. S. Chelladurai, and R. Ramamoorthi, "Experimental investigation of the effect of various chemical treatments on agave angustifolia marginata fibre," in Green Materials and Advanced Manufacturing Technology, pp. 173-190, CRC Press, 2020.

[11] S. Luo and A. N. Netravali, "Interfacial and mechanical properties of environment-friendly "green" composites made from pineapple fibers and poly (hydroxybutyrate-co-valerate) resin," Journal of Materials Science, vol. 34, no. 15, pp. 3709-3719, 1999.

[12] V. S. Sreenivasan, S. Somasundaram, D. Ravindran, V. Manikandan, and R. Narayanasamy, "Microstructural, physico-chemical and mechanical characterisation of Sansevieria cylindrica fibres - an exploratory investigation," $M a$ terials \& Design, vol. 32, no. 1, pp. 453-461, 2011.

[13] N. S. Venkatesha Gupta, K. S. Akash, K. V. Sreenivasa Rao, and D. S. Arun kumar, "Fabrication and evaluation of mechanical properties of alkaline treated sisal/hemp fiber reinforced hybrid composite," IOP Conference Series: Materials Science and Engineering, vol. 149, no. 1, Article ID 012093, 2016.

[14] K. S. Rao and N. V. Gupta, "Mechanical properties of sisal/ coir fiber reinforced hybrid composites fabricated by cold pressing method," IOP Conference Series: Materials Science and Engineering, vol. 149, no. No. 1, Article ID 012092, 2016.

[15] T. Ramakrishnan and P. S. Sampath, "Experimental investigation of mechanical properties of untreated new Agave Angustifolia Marginata fiber reinforced epoxy polymer matrix composite material," Journal of Advances in Chemistry, vol. 13, no. 4, pp. 6120-6126, 2017.

[16] M. A. Kabir, M. M. Huque, M. R. Islam, and A. K. Bledzki, "Mechanical properties of jute fiber reinforced polypropylene composite: effect of chemical treatment by benzenediazonium salt in alkaline medium," Bioresources, vol. 5, no. 3, pp. 1618-1625, 2010.

[17] M. Haque, N. Islam, M. Huque, M. Hasan, S. Islam, and S. Islam, "Coir fiber reinforced polypropylene composites: physical and mechanical properties," Advanced Composite Materials, vol. 19, no. 1, pp. 91-106, 2010.

[18] P. A. Sreekumar, S. P. Thomas, J. m. Saiter, K. Joseph, G. Unnikrishnan, and S. Thomas, "Effect of fiber surface modification on the mechanical and water absorption characteristics of sisal/polyester composites fabricated by resin transfer molding," Composites Part A: Applied Science and Manufacturing, vol. 40, no. 11, pp. 1777-1784, 2009.

[19] M. R. Rahman, M. M. Huque, M. N. Islam, and M. Hasan, "Mechanical properties of polypropylene composites reinforced with chemically treated abaca," Composites Part A: Applied Science and Manufacturing, vol. 40, no. 4, pp. 511-517, 2009.

[20] R. O. Akaluzia, F. O. Edoziuno, A. A. Adediran, B. U. Odoni, S. Edibo, and T. M. A. Olayanju, "Evaluation of the effect of reinforcement particle sizes on the impact and hardness properties of hardwood charcoal particulate-polyester resin composites," Materials Today Proceedings, vol. 38, pp. 570-577, 2021.

[21] E. M. Araújo, K. D. Araújo, O. D. Pereira, P. C. Ribeiro, and T. J. de Melo, "Fiberglass wastes/polyester resin composites: mechanical properties and water sorption," Polímeros, vol. 16, pp. 332-335, 2006.

[22] S.-J. Park and J.-S. Jin, "Effect of silane coupling agent on interphase and performance of glass fibers/unsaturated polyester composites," Journal of Colloid and Interface Science, vol. 242, no. 1, pp. 174-179, 2001.

[23] A. Lavoratti, L. C. Scienza, and A. J. Zattera, "Dynamicmechanical and thermomechanical properties of cellulose nanofiber/polyester resin composites," Carbohydrate Polymers, vol. 136, pp. 955-963, 2016. 